\title{
Economic homeostasis through negative feedback in the market using a floating taxation policy: an initial insight
}

\author{
By Dimitri Marques Abramov \\ Laboratory of Neurobiology and Clinical Neurophysiology \\ National Institute for Women, Child and Adolescent Health Fernandes Figueira \\ Fundação Oswaldo Cruz - Brazil
}

\begin{abstract}
The market economy is contemporaneously considered as a complex adaptive system, chaotic and far from equilibrium. However, there are no feedback mechanisms that provide stability to the system. In this preliminary essay, I outline the fundamental idea of a floating taxation system to compensate the market oscillations of goods, growth and profit of companies and their socio-environmental impact, promoting the long-term stability of the economic system.
\end{abstract}

\section{Author Presentation}

First of all, I am a physiologist. I often say that I am a generalist physiologist, more concerned with a holistic view than with the study of segmented processes. Therefore, I have extrapolated the classical domain of physiology far beyond the understanding of how living organisms work, seeking to observe physiological paradigms in all known nature. I started walking this path 22 years ago when I came across the contemporary thinking of men like Prigogine, Maturana, Capra, Lorenz, Poicaré, Boltzmann, and so many others, who cast a doubt on the Newtonian and Laplacian mechanicist thinking.

Thus, from my standpoint, the world is no longer made of finite substances. It has become a set of multidimensional processes organized as chaotic systems. I have been trying since then to understand better the science of complex systems, which works in a different kind of reality, until very recently alien to the traditions of natural and social sciences. I have spent a great deal of time reading Spinozist ethics that upscaled my understanding of the universe as relationships (dynamical processes) between systems, and complexity.

Unfortunately, to date I have not had the opportunity to ostensibly study and work academically on the science of complexity, or on its scientific and philosophical developments. I took my academic training in neurosciences and have been dedicated to research and technological development at the Oswaldo Cruz Foundation for the last five years. I have consolidated my professional career in psychiatry over 18 years, because of necessities of life.

However, I am convinced that the worldview through chaos/complexity has made me an unconventional physician. In many instances, I perceive non-negotiable conflicts with the classical thinking in which we are trained in clinical praxis. I believe that one of the greatest academic challenges of humankind will be to resolve this conflict. In my opinion, the fundamental pillar of a sustainable world depends on that solution. We need to learn to see beyond our academic microscopes. 
Nature is a set of complex interactive processes among systems that are organized in an emerging way by the same "thermodynamic" paradigms (I prefer "paradigm" over "law"), in different levels of organization (like fractals). For example, the concept of entropy is applied to models for quantal physics, molecular biology, organic systems, psychology, even sociology, economics, and ecology. Therefore, there is something in common in all disciplines of observational knowledge about the Universe: the organizational paradigms of their processes and systems, ranging from the non-complex (drifting in the environment) to the complex ones, are based on the dynamic emergence of patterns of order and stability through chaos.

\section{Transdisciplinarity}

As an intellectual practice, I see transdisciplinarity as a contemporary initiative in search of holistic knowledge of the Universe by (1) overcoming a substantial view of the most diverse natural systems for a vision of interactive processes (networks); (2) assessing the evolution of these processes; (3) understanding the chaotic (but deterministic) mechanics of the emergence of order patterns far from the thermodynamic equilibrium - complexity; (4, which is of great importance to us) understanding the stabilization processes of the complex systems for the (5) application of this fundamental science in the different disciplines to understand their particular cases of natural / social phenomenology (e.g., economy) and intervention in light of this knowledge.

Thus, transdisciplinarity is the most important intellectual initiative to achieve the ideal of a prosperous, sustainable, and socially / technologically developing world. Because the transdisciplinary viewpoint feeds the world with models we need to build by envisioning the perseverance of humanity (our collective ideal for a long and prosperous life). The fact is that intellectual doctrines based on the technological and economic development of society need to be reviewed through this transdisciplinary viewpoint, which understands economy as a natural system governed by the same paradigms as the entire Universe.

However, understanding the path to achieve this goal of transdisciplinary initiative is a difficult and strange exercise for a civilization that has been exclusively dedicated to the development of the analytical skills of the mind for 500 years. It is difficult for me to translate "transdisciplinarity" verbally. However, I feel its quintessence in the poetic images brought to us by art of a nature without delimitations. I believe that this is the imaginary of the academics of transdisciplinarity and complexity. Yet, this is another discussion.

In mental health practices in Brazil, the transdisciplinary viewpoint is an actual public policy, with positive results in the integration of the so-called "patient" within the community. The (still utopian) aim of these policies is to question the analytic / reductionist clinical practice that delineates a nosological label and a priori limits the degrees of freedom of the individual. Thus, Brazilian mental health seeks the individual functionalities and potentialities for a diverse social context. In other words, we try to tread an ethicalfunctional path and not the ontological-nosological ones.

I believe that, in a way, this deconstruction must go through all disciplines to reach pragmatically the desirable, if not necessary, world for our future as humanity. 


\section{Complexity and homeostasis}

The science of complexity realized that the climax of complexity in the natural world was the manifestation of LIFE. This life would be thus pragmatically defined by Prigogine [01] as "a dissipative process" in "a complex, stable system far from equilibrium". This dynamic stability is the key to life. The temperature of the human body must be stable (more or less constant) despite fluctuations in room temperature. This is what we call HOMEOSTASIS [02].

This stability is an emergent, i.e., self-organized process. There are no living organisms with a "command center" that a priori drives the temperature, despite a regulatory center in the hypothalamus. The organism finds a balance (at the expense of much energy) between its systems through a process called feedback. If the internal temperature rises, the peripheral vessels expand. If the internal temperature drops, muscles begin to contract to produce more heat (cold tremors). Vessels, blood, muscles, hormones throughout the body are interconnected in a network of interactive processes, some modulating others (inhibiting, decelerating, etc.). Control of the organism as a whole is determined by the organism as a whole, in the dynamic balance of its parts, seeking a dynamic functional stability condition (which must not be confused with thermodynamic equilibrium). Like a tightrope player who controls his/her swing using the stick on the rope trying to maintain stability while walking.

Once Homeostasis has been achieved, the whole assembly of trillions of cells can then reproduce, evolve, adapt to the world around it. Homeostasis is the keystone of an enduring life.

The theory of Gaia [03] considers the biosphere as a great living organism because it is a complex adaptive system far from thermodynamic equilibrium [04]. The Biosphere evolves as a planetary system that maintains its own stability (atmospheric composition, average temperature, for example) at the expense of solar energy, through the dynamic integration of its ecosystems and the geophysical systems that support them. These systems provide feedback on each other by distributed and self-organized control processes throughout the Earth's crust and atmosphere, just as muscles and blood vessels keep body temperature almost constant.

Ecosystems are generally formed by feedback processes that maintain the stability of populations and their surrounding environment. The human gut is a complex ecosystem where hundreds of bacterial and fungal species maintain their harmonious coexistence and the vitality of their environment in a self-organized network through feedback processes. Reducing certain bacterial populations (by the indiscriminate use of antibiotics, for example) allows for the disordered growth of pathogenic streams, which destroy ecosystem stability.

Generally, the system tends to collapse by the lack of control through feedback. When there is a sudden, small reduction in the oxygenation of lake water, anaerobic bacteria find the opportunity to reproduce rapidly, producing substances that further decrease oxygen in the water. Other organisms in the lake begin to die of hypoxia, serving as food for these bacteria, which reproduce even more, exponentially speeding up the destruction process of the lake ecosystem. These processes of self-destruction are positively feedbacked leading to an asymmetry, to exponential progression of an instability process to the point of resource collapse and widespread death. 
In general, death is caused by processes of positive feedback, resulting from the breakdown of homeostasis somewhere in the system [02, 05].

Therefore, it is possible that a small human disturbance (such as raising the temperature of the earth by a single degree because of our fossil fuels) can produce a breakdown of planetary homeostasis and the whole biosphere enters into an accelerated and irreversible self-destruction process, which can sweep the life off the planet in a short time. A Big Extinction.

Stability of global economy, which results from the ups and downs of crashes and booms, is a goal frequently pursued. However, without homeostasis, can economy perpetuate itself in constant evolution? How to establish this homeostasis? Through a wild and autocatalytic capitalism, and/or through a planned and controlling state, which is thus "over-bureaucratic" and expensive in its interventionist mission?

Here the physiologist ends his discourse and enters a strange world as a layman.

\section{About the economic system}

The characteristics of the complex, multidimensional, dynamic nature of economy are evident, and it is extremely sensitive to disturbances in its environment (initial conditions). Disturbances can lead to the establishment of neoliberal empires or even to global bankruptcy. The market economy can be regarded as an adaptive complex system that evolves far from equilibrium [06, 07], based on a self-organized balance between offer and demand in a multilevel (micro to macroeconomy) and multidimensional (biocognitive/psycho-social) organization, interacting with other macrossystems.Despite my superficial knowledge about it, I think that the economic general equilibrium theory [08] has brought some insights about the self-organization of a complex and chaotic system. However, this theory assumes a priori that the economy tends to equilibrium despite external perturbations. If this assumption are correct, we cannot explain exponential growing of some companies from their millieu, for example, characterizing the market economy a chaotic complex system far from thermodynamic equilibrium.

However, are there mechanisms providing stability (homeostasis) to the market economy? This exponential growth by positive feedback would corrupt the system stability as a whole or in part. The market should to prevent its agents from being like the anaerobic bacterium that devastates the lake at the first opportunity, if it intends to be perennial.

In my view, it is inconceivable that a man or corporation concentrates the power of continental nations as a consequence of a flagrantly positive feedback process, that started by chance, due to an opportunity within the initial conditions and "tilt the competitive balance" [09]. In my opinion as layperson, inequality, social injustice, barbarism in underdeveloped nations, global corruption, etc., which concretely threaten the future of humanity and the Earth, would be related to the lack of market self-regulation mechanisms.

Each day the State is farther from fulfilling its mission of regulating market economy. I am not a theorist of the state; I have read little about the works of these thinkers. Nevertheless, to my empiricist senses, the state is an anachronistic and ineffectual machine, operating through the ideal of control centralization, of the illusion of the 
Cartesian homunculus set in the pineal of the world to dictate how the clock (which does not exist) should work. The state is a planned entity, feedforwardly acting over society and markets, which will always fall short of the rapid dynamics of them, which become complex as the technological and social milieu develops and advances, and the offer of goods is diversified. The control of market economy (institutional) by the State is an "artificial" process in pursuit of an unattainable ideal. As fast as it can be, it will never be in synchronicity with how fast reality in the markets changes. Thus, state intervention is incompatible with the complexity of the contemporary market. The state seems still to be rooted in the Newtonian-Laplacian illusion of a mechanical, linear world.

However, the "liberal" market for free initiatives is necessary because self-organization of chaotic processes is the fertile ground for the emergence of novelty, adaptation and evolution. Private property, pro-labore, and profit are still necessary because they satisfy the materialist human desire (of contemporary man, at least). All this is necessary for a world with the comfort of smartphones, with the safeguarding of antibiotics or with the longevity in Denmark. However, there are no homeostatic mechanisms to provide stability for the great economic ecosystem to evolve, boosting the development of humanity with ecological sustainability. In my opinion, there is no homeostatic mechanism in economy to ensure the long-term survival of this ecosystem.

\section{Physiological Homeostasis for transdisciplinary Economics.}

Tax may be the oldest alliance between Market/society and State, as a secular contract. Nevertheless, taxes have never been treated (as far as I know) as an element of a feedback loop from the market. Tax policies are planned according to the budget needs of the states. But the tax rates can be used for manipulate the market, in an attempt to avoid crises or to control sectors of the Economy. However, they are, as I said, planned processes that are not synchronized to market dynamics.

I have been thinking of a self-regulation process of market economy that is, however, extrinsic to the market itself, centralized in a policy of floating taxes that can dynamically feedback the system from (1) changes in prices of goods, (2) growth and contraction of companies (based on their market value or nominal profit) and (3) the social and environmental impact of business activities, ensuring its stability over time and sufficient freedom for its evolution. The implementation of a dynamic system that allows for floating taxation in response to market fluctuations would contribute to economic homeostasis. The process of tax fluctuation probably would not have the same iteration speed as the market's intrinsic fluctuation processes, but could, even in a relatively short time window, modulate the oscillations of the economy in a self-organized way.

(I have made a persistent search in references to precedents of what I am now going to outline. I did not find anything substantial about).

The fluctuations of currency exchange and stock and commodity exchanges are clearly feedback processes (positive and negative), but, in my opinion, do not contribute with the stability of the economy as a whole quite the opposite, they feed violent oscillations. This is because they are processes intrinsic to the market system, not directly modulated by the universe that holds the market and supports it.

For its effectiveness, procedures for monitoring market values and conducts should be established so that they can automatically modulate tax rates at a "high speed". For 
instance, when a given product is depreciated for any reason (a stochastic oscillation of the price of sugar in the market not caused by the natural offer/demand balance), taxes on this product are rapidly, automatically, and proportionally reduced, preserving its market profit, intended for sectorial recovery. Likewise, the increase in the price of this product would lead to a proportional and automatic increase in the taxes levied on it, offsetting the tax reduction of the "downward" sectors of the economy.

In a broader context, floating taxation could act over the growth or retraction of companies, with a view to inhibiting the oligopolization of the market, producing significant economic asymmetries that compromise the freedom of the consumer and free initiative. One example are networks that oligopolize and control the services sector, commerce, or even the financial market. The growth of a retail business company becomes exponential the moment it breaks down smaller competitors and controls the supplier system. Floating taxation could equalize the final cost of the service according to the size of the companies in the economic sectors proportional to the nature of their activities.

The floating tax system has a price. The sugar producer, the supermarket owner, or the banker will not become excessively rich, but they also have the assurance that they will not suddenly impoverish. The long-term consequence of stability (risk reduction) will probably be the equalization of the distribution of wealth in society, produced by the market itself as a whole, through its self-organization driven by a feedback mechanism through floating taxation.

One of the main scourges that follows the growth of market economy is its environmental and social burden. Particularly the social cost increases the environmental cost.

Economically inequal societies more significantly compromise the environment [10]. We remember that the environment, as biosphere, is a dissipative stystem, stable but far from equilibrium. Minimal disturbances can produce positive feedback loops that would lead us to planetary collapse. Thus, the floating taxation mechanism transcends Market Economy to achieve Planetary Economy. In this sense, there are precedents regarding the taxation of miners (product and service) according to their environmental impact [11]. The red flag in the Brazilian light bill has the same purpose: to modulate production or consumption for the benefit of the environment [12]. This policies prototypically follow this logic, but without sufficient dynamics for really feedbacks the market.

However, the market would be regulated dynamically by floating tax rates concerning the environmental impact of the production or consumption of goods by each economic activity or mode of production. The rationale may be an economic thesis: the financial cost of a polluting process is higher, which raises the cost of government, which is responsible for cleanup. Causing Burnout Syndrome in the exploited worker raises the cost of the state, which must bear the burden of health and social security system. In the case of minimal states (with private health and social security), occupational disease is a way of subtracting wealth from others, from health insurers and private pension funds. Similarly, water pollution by a chemical industry subtracts wealth from the agribusiness that depends on that water. The market, once again, dynamically modulates itself through state floating taxation.

Although the State is performing the role of "controller" (as the hypothalamus in relation to immunoendocrine systems and metabolism), this is only a pictorial representation in these self-organized (emergent) processes for a comprehensive view based on reductionist systematization. In economical homeostatic system, the role of the state is in fact far from the Keynesian model for market economy. The state is a mere catalyst for the economic 
homeostatic processes integrated to the universe that surrounds the market (either society or the terrestrial environment), through a "modulating hormone" (functionally known as "tax", and ontologically defined as "money") whose release is influenced by dynamic processes extrinsic to the market, but that also sustain it. Some quantitative parameters, as sensitivity thresholds and elapsing times between state measures would set the system evolution.

\section{Conclusion}

I hypothesize that a government system of floating taxation that modulates the relationships between the market and its surrounding universe by feedback, in a selforganized and dynamic way, will give stability to the economy on a global scale and the perenniality of the own market, preventing autocatalytic grown processes, allowing the continuous evolution of society with equalization of wealth coupled with free initiative and individual prosperity, concerning the patterns of complex systems of nature with vital properties.

If homeostasis has worked well in nature for a billion years allowing the evolution of life in all its diversity, why would it not work in the market economy?

\section{References}

01. Prigogine I, Stengers I. The End of Certainty. The Free Press, 1997. ISBN 978-0-68483705-5.

02. Mourão Junior CA, Abramov DM. Fisiologia Essencial. Rio de Janeiro: Ed. GuanabaraKoogan. 2010.

03. Onori L, Viscont G. The GAIA theory: from Lovelock to Margulis. From a homeostatic to a cognitive autopoietic worldview. Rendiconti Lincei. 2012; 23(4): 375-386.

04. Levin SA. Ecosystems and the Biosphere as Complex Adaptive Systems.

Ecosystems1998; 1(5):431-436

05. Mourão Junior CA, Abramov DM. Biofísica Essencial. Rio de Janeiro: Ed. GuanabaraKoogan, 2011.

06. Arthur WB. Complexity and the Economy. Science. 1999; 284(107): 107-109.

07. Helbing D, Kirman A. Rethinking economics using complexity theory. Real-World Economics Review, issue no. 64. Accessed at:

https://www.semanticscholar.org/paper/Rethinking-economics-using-complexity-theoryHelbing-Kirman/7bf25340a21dbbf9ec8bbc3175524a0fe4618f07

08. Tobin J. A General Equilibrium Approach To Monetary Theory. Journal of Money, Credit and Banking, 1969. 1(1): 15-29

09. Arthur WB. Positive feedbacks in the economy. Scientific American. 1990; 262(2):9299

10. Dorling D. The rich, poor and the earth. The New Internationalist. 2017. Accessed at: 
https://newint.org/features/2017/07/01-equality-environment.

11. Robertson J. SHARING OUR COMMON HERITAGE: RESOURCE TAXES AND GREEN DIVIDENDS. Proceedings of a One-Day International Conference Held by the Oxford Centre for the Environment, Ethics and Society at Rhodes House, Oxford on Thursday 14 May 1998. Avaiable at

<http://www.jamesrobertson.com/book/sharingourcommonheritage.pdf>

12. Light Company. Bandeiras Tarifárias (Tax flags). (in portuguese) Accessed at http://www.light.com.br/para-residencias/Informacoes/bandeiras_tarifarias.aspx

13.Tesfatsion L. Agent-based computational economics - modelling economies as complex adaptive systems. Information Sciences. 2003; 149(4): 262-268 